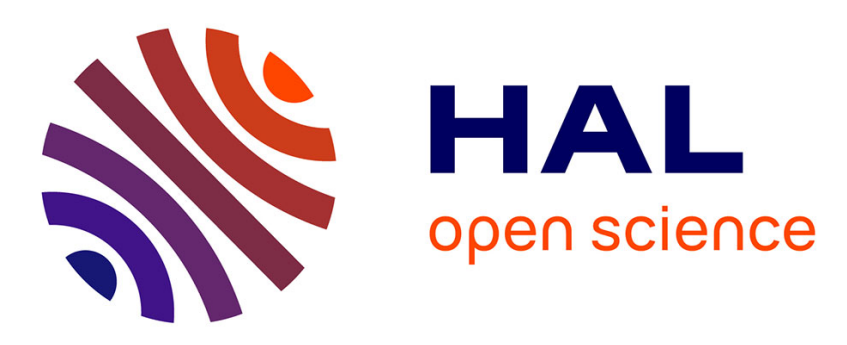

\title{
Evaluation of liquid transport properties of hydrophobic polymers of intrinsic microporosity by electrical resistance measurement
}

Alexey Yushkin, Vladimir Vasilevsky, Valery Khotimskiy, Anthony Szymczyk, Alexey Volkov

\section{To cite this version:}

Alexey Yushkin, Vladimir Vasilevsky, Valery Khotimskiy, Anthony Szymczyk, Alexey Volkov. Evaluation of liquid transport properties of hydrophobic polymers of intrinsic microporosity by electrical resistance measurement. Journal of Membrane Science, 2018, 554, pp.346-356. 10.1016/j.memsci.2018.03.022 . hal-01771096

\section{HAL Id: hal-01771096 \\ https://hal-univ-rennes1.archives-ouvertes.fr/hal-01771096}

Submitted on 6 Jul 2018

HAL is a multi-disciplinary open access archive for the deposit and dissemination of scientific research documents, whether they are published or not. The documents may come from teaching and research institutions in France or abroad, or from public or private research centers.
L'archive ouverte pluridisciplinaire HAL, est destinée au dépôt et à la diffusion de documents scientifiques de niveau recherche, publiés ou non, émanant des établissements d'enseignement et de recherche français ou étrangers, des laboratoires publics ou privés. 


\title{
Evaluation of liquid transport properties of hydrophobic polymers of intrinsic microporosity by electrical resistance measurement
}

\author{
Alexey Yushkin ${ }^{1}$, Vladimir Vasilevsky ${ }^{1}$, Valery Khotimskiy ${ }^{1}$, Anthony Szymczyk ${ }^{2}$, Alexey \\ Volkov $^{1 *}$
}

\author{
${ }^{1}$ A.V.Topchiev Institute of Petrochemical Synthesis RAS, Moscow, Russia \\ ${ }^{2}$ Univ Rennes, CNRS, ISCR (Institut des Sciences Chimiques de Rennes) - UMR 6226, F-35000 \\ Rennes, France \\ *avolkov@ips.ac.ru
}

\begin{abstract}
In this work, the electrical resistance method was used to get an insight of the liquid transport through the polymers with excess of fractional free volume. The dense films based on the first generation of polymers of intrinsic microporosity, disubstituted polyacetylenes PMP and PTMSP, were used; water-ethanol binary mixtures allowed to adjust the affinity of the liquid phase to selected polymers continuously. In this work, the liquid-membrane interaction was considered as a stepwise occupation of accessible free volume elements within the polymer, while the appearance of continuous (pseudo)liquid channels in the polymeric matrix, so-called percolation clusters, was required for formation of hydrodynamic liquid transport. Since the appearance of such percolation clusters might dramatically change the conductivity of hydrophobic materials, it was proposed to use the electrical resistance method to investigate the evaluation of selected polymers from being a barrier (water) to being permeable (ethanol) with respect to the liquid composition. To highlight the electrical resistance of the swollen films, all water/ethanol solutions contained $\mathrm{NaCl}(0.5 \mathrm{~g} / \mathrm{L})$. The steady-state values of liquid permeation, sorption/swelling, and electrical conductivity data were considered together and discussed. The electric resistance was significantly varied for $30 \mu \mathrm{m}$ dense films of PMP (1-1300 k $\Omega$ ) and PTMSP (0.15-910 k $\Omega$ ) by the adjustment of ethanol content in water. The phase shift (25$100000 \mathrm{~Hz}$ ) illustrated that the behavior of PTMSP and PMP membranes changed from mainly capacitive at low ethanol concentrations to the ion conductive as higher ethanol content. The very good quantitative agreement was found between the relative change of the membrane electrical resistance and the permeability as a function of the ethanol content in the liquid phase. Consequently, electrical resistance measurements could be used as an express method to determine the membrane permeability of low permeable materials, since the time required to get
\end{abstract}


steady-state results was found to be much shorter for electrical resistance measurements than for permeability measurements.

Keywords: PTMSP, PMP, electrical resistance, filtration, prediction of liquid permeability.

\section{Introduction}

The biggest membrane applications in the industry are related to different kinds of liquidbased separation processes $[1,2]$. In some applications such as filtration or (electro)dialysis, the membrane is supposed to be wetted by the liquid phase in order to realize the transport of solvent molecules across the membrane. In opposite, the gas-liquid contactor systems (e.g., membrane distillation) can be successfully operated on the long-term basis only if the membrane pores are filled by the gas phase despite the fact that one or two sides of the membrane are contacted with the liquid. With regard to the liquid properties, first of all, its surface tension, the same porous membrane based on, for example, poly[tetrafluorethylene] (PTFE) or poly[vinylidenefluoride] (PVDF) can be used in the gas-liquid contactors for $\mathrm{CO}_{2}$ capture, water desalination or filtration processes [3-6]. In the case of high-pressure applications like solvent nanofiltration or gas-liquid contactor systems, the membrane top-layer is usually made of the non-porous (elastomeric polymers) or microheterogeneous (glassy polymers) materials [5,7,8].

The liquid transport across the membrane is usually determined by the filtration method using dead-end or cross-flow membrane cell. However, long-term experiments are required for characterization of barrier or semi-permeable materials due to the sensitivity of the method from about $10^{-5} \mathrm{~kg} / \mathrm{m}^{2} \cdot \mathrm{h} \cdot$ bar. Recently proposed dynamic pressure decay self-calibration technique [9] allows to improve further the sensitivity from $5 \cdot 10^{-7} \mathrm{~kg} / \mathrm{m}^{2} \cdot \mathrm{h} \cdot \mathrm{bar}$, but higher pressures are required for better detection of liquid transport.

At the same time, the liquid filtration process is not attributed to the phase transition like other membrane processes such as pervaporation or membrane distillation. Therefore, the hydrodynamic flow through the membrane can be conducted only through percolation clusters available within the membrane matrix regardless of the material nature and porous structure of selective layer. By this mean, it is expected that such transport "channels" are continuously formed through interconnected vacant sites from upstream to downstream sides of the membrane. In the case of rubbery polymers, the free volume elements appear due to the statistical fluctuation of the polymer segments, and if the size of the vacant position is comparable with the size of solvent molecules, the transport could occur within the membrane.

For the glassy polymers, interconnected free volume elements are naturally or artificially formed during the membrane preparation and are more likely fixed in time due to the more rigid 
structure of the matrix. In the case of glassy polymers with a high fractional free volume such as substituted polyacetylenes or PIM-1, the solvent transport through the swollen polymeric matrix is mostly determined by the fraction of pre-existing interconnected free volume elements rather than the additional free volume elements appeared upon polymer swelling [10]. For the liquids with a limited wetting capability, these polymers might be impermeable even at elevated pressures, and it becomes permeable with the increase of wetting component fraction in the binary mixture [10,11]. Such observed threshold values of sorption, swelling degree, and fractional accessible volume were explained by stepwise accommodation of free volume elements with the solvents molecules and the phenomena of percolation cluster formation. The percolation theory is widely used to describe the phenomena of formation of connected networks between randomly placed clusters or species on micro- or macroscale that enable the continuous flow or pathways from one side to another side of the objects [12-17]. For example, a percolation model was proposed to describe the adsorption and desorption process in the porous media, including the hysteresis effect [13]. Non-linear increase and certain threshold in the electrical conductivity, mechanical properties, dielectric permittivity, magnetic or gas permeability can be found when the fillers such as carbon nanotubes (CNT) or magnetic particles are introduced in the polymeric matrix [15-19]. Furthermore, the threshold concentration of CNT is a function of their geometrical characteristics, and nonlinearly decreases with increasing their aspect ratio $[16,17]$.

The solvent clusters accommodated within vacant positions of the membrane matrix can be considered as a liquid or pseudo-liquid phase that still possesses macroscopic properties like bulk viscosity or electrical conductivity. This enables to utilize different techniques for characterization of the membrane properties. For example, the electrical properties of the different membrane sub-layers can be inferred from impedance measurements over a range of frequencies (impedance spectroscopy) [20-28]. The most used technique is the difference method in which the membrane resistance is obtained from the difference between the cell resistance measured in AC mode with and without the membrane [22-30]. For most experimental devices the current lines are normally oriented to the membrane surface and the system made up of the membrane surrounded by two identical solutions is then equivalent to an electrical circuit with serially-connected elements. Other cell configurations, with a parallel association of the membrane and the measuring solution, have been proposed to characterize membranes that are much more conductive than the measuring solution [29].

Electrical conductivity is one of the most important characteristics of ion-exchange membranes [31-34] but also measuring of electrical properties make it is possible to estimate the thickness of active layer in reverse osmosis or nanofiltration membranes [20-22,35], porosity of 
porous sublayers [25,26,36], monitoring of deposition (fouling) on top of the membrane $[25,26,36]$, to get insight in the transport behavior of different charged species within the membrane $[21,23]$ or evaluate the wetting of microporous hydrophobic membranes used in membrane contactors [27]. It should be noticed that electrical impedance spectroscopy is widely used for characterization of resistance and capacitance of active and porous sub-layers of reverse osmosis membranes [20], nanofiltration membranes [20-22,35], evaluation of (bio)fouling [25,26,36], water presence and ionic liquid loss in supported liquid membranes [37], monitoring of membrane modification with the charged species [38], wetting of porous membranes used in membrane contactors [27] and study of piezoelectric properties of porous membranes [39].

In this work, the formation of percolation clusters inside dense polymer membranes was highlighted by the determination of the membrane electrical resistance in electrolyte/water/ethanol systems. The wettability properties of the liquid phase were modified by changing the ethanol to water ratio in the different mixtures. Poly[4-methyl-2-pentyne] (PMP) and poly[1-(trimethylsilyl)-1-propyne] (PTMSP) were selected as membrane materials since both of them were investigated for solvent nanofiltration and high-pressure gas-liquid membrane contactor applications $[11,40]$.

\section{Experimental part}

\subsection{Polymers and membrane formation}

PTMSP was synthesized by polymerization of 1-(trimethylsilyl)-1-propyne in toluene solution using $\mathrm{TaCl}_{5}$ as the catalyst with co-catalyst triisobutylaluminum (TIBA) [41]. Polymerizations were carried out under the following conditions: [Monomer $] /[$ Catalyst $]=50$, $[$ Cocatalyst $] /[$ Catalyst $]=0.3, \quad[\text { Monomer }]_{0}=1 \quad \mathrm{~mol} / \mathrm{l}, \quad \mathrm{T}=25^{\circ} \mathrm{C} \quad\left(M_{\mathrm{w}}=1.0 \cdot 10^{6}, \quad M_{\mathrm{w}} / M_{\mathrm{n}}=2.9\right.$, $[\eta]_{\text {toluene }}^{25} 6.4 \mathrm{dl} / \mathrm{g}$ ). PMP was synthesized by polymerization of 4-methyl-2-pentyne in cyclohexane solution with the catalytic system $\mathrm{NbCl}_{5} / \mathrm{Et}_{3} \mathrm{SiH}$ [42]. Polymerization was carried out under the following conditions: [Monomer]/[Catalyst]=50, [Cocatalyst]/[Catalyst]=1, $[\text { Monomer }]_{0}=1 \mathrm{~mol} / \mathrm{l}, \mathrm{T}=25^{\circ} \mathrm{C}\left(M_{\mathrm{w}}=1.2 \cdot 10^{6} M_{\mathrm{w}} / M_{\mathrm{n}}=2.1,[\eta]^{25}{ }_{\text {cyclohexane }}=3.2 \mathrm{dl} / \mathrm{g}\right)$.

The dense PTMSP or PMP membranes were cast from solution with a polymer concentration of $0.5 \mathrm{wt}$ \% (solvent: chloroform) onto commercial cellophane. Then the cast film was covered with a Petri dish and left for slow evaporation for several days, followed by drying in the oven at $40^{\circ} \mathrm{C}$ to constant sample weight. Further treatment of all membranes was according to the standard protocol of membrane preparation [43], which includes soaking the membrane samples in n-butanol (2 days) and aqueous ethanol solutions with stepwise decreasing of alcohol concentration from $96 \%$ to $0 \%$ ( 2 days) followed by drying at ambient conditions (1 day). Thicknesses of obtained membranes were $30 \mu \mathrm{m}$. 


\section{ACCEPTED MANUSCRIPT}

\subsection{Electrical conductivity measurements}

Membrane electrical resistance measurements were performed with the lab-made experimental device depicted in Figure 1. The experimental setup was composed of two identical chambers of $150 \mathrm{~mL}$ each. The membrane, with an active surface area of $12.6 \mathrm{~cm}^{2}$, was placed in between the chambers and sealed. Both chambers were filled with the same solution in order to avoid concentration gradient across the membrane during the experiment. Platinum electrodes with a surface area of $24 \mathrm{~cm}^{2}$ were used, the distance between the electrodes and the membrane being set to $35 \mathrm{~mm}$. Electrical resistances were measured with an LCR meter E7-20 at atmospheric pressure at the frequencies from 25 to $10^{5} \mathrm{~Hz}$ and voltage of $0.05 \mathrm{~V}$; the current was measured with amperemeter at a voltage of $0.5 \mathrm{~V}$. For each liquid phase composition, the resistance was measured after at least 4 hours, which allowed reaching the steady-state. The resistance of the system was a combination of the resistances of the two chambers and that of the membrane in series. The resistance of the solutions was determined independently by measurements without the membrane at the same frequencies. Water/ethanol mixtures with various compositions (from 0 to $96 \%$ of ethanol) were used to adjust the wettability properties of the liquid phase. $\mathrm{NaCl}$ was added to all solutions $(0.5 \mathrm{~g} / \mathrm{L})$ in order to increase the electrical conductivity of liquid phase.

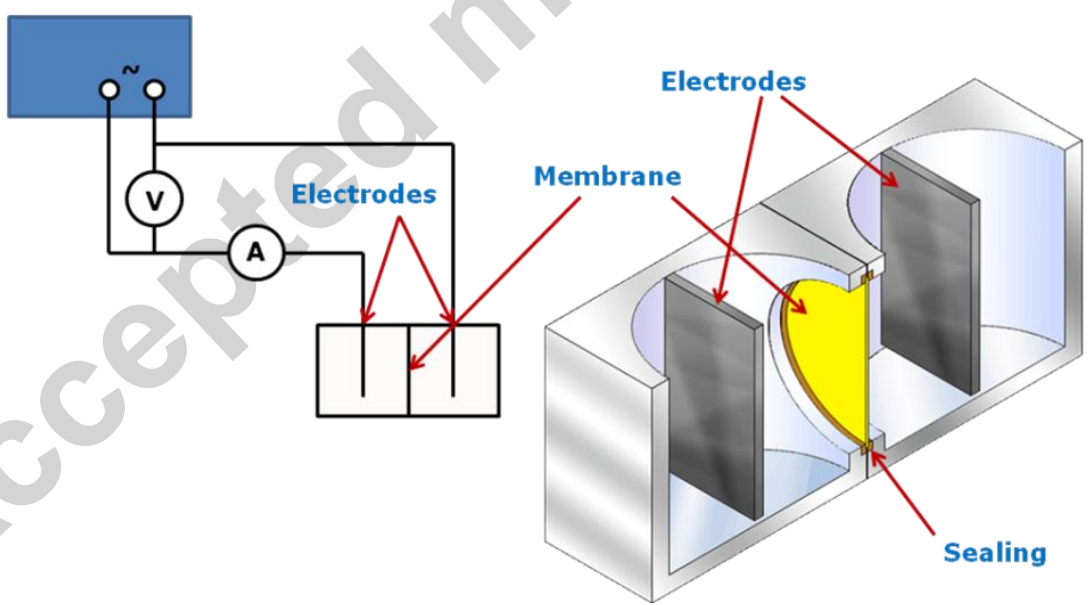

Fig 1. Experimental setup for membrane resistance measurement.

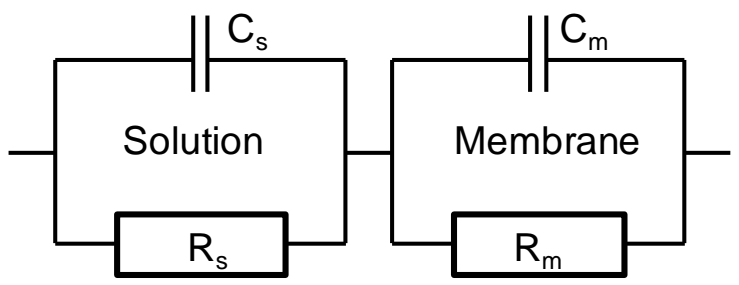

Fig 2. Equivalent circuit of experimental setup. 
In this work, the equivalent circuit was considered as a series of two elements - membrane and solution expressed by resistance $\left(R_{m} ; R_{s}\right)$ and capacity $\left(C_{m} ; C_{S}\right)$ as illustrated on Figure 2. The circuit conductivity $(\sigma)$ of the single element consists of the capacitor $(C)$ and resistance $(R)$ in parallel can be expressed as a function of frequency $(f)$ :

$$
\begin{gathered}
\sigma=\frac{1}{R}+j 2 \pi f C=|\sigma| e^{-j \varphi} \\
|\sigma|=\frac{\sqrt{1+(2 \pi f)^{2} C^{2} R^{2}}}{R} \\
\varphi=\operatorname{arctg}(2 \pi f C R)
\end{gathered}
$$

The overall impedance $(Z)$ of the system can be expressed as follows:

$$
\begin{aligned}
Z=\frac{1}{\left|\sigma_{s}\right|} e^{j \varphi}+ & \frac{1}{\left|\sigma_{m}\right|} e^{j \varphi}=R e Z+j \operatorname{Im} Z \\
& =\frac{R_{s}}{1+(2 \pi f)^{2} C_{s}^{2} R_{s}^{2}}+\frac{R_{m}}{1+(2 \pi f)^{2} C_{m}^{2} R_{m}^{2}} \\
& +j\left(\frac{2 \pi f C_{s} R_{s}^{2}}{1+(2 \pi f)^{2} C_{s}^{2} R_{s}^{2}}+\frac{2 \pi f C_{m} R_{m}^{2}}{1+(2 \pi f)^{2} C_{m}^{2} R_{m}^{2}}\right)
\end{aligned}
$$

The capacity $\left(C_{\mathrm{s}}\right)$, phase shift $\left(\varphi_{\mathrm{s}}\right)$ and real part of impedance $\left(\operatorname{Re} \mathrm{Z}_{\mathrm{s}}\right)$ for the solution were determined from the experiments when a corresponding solution without a membrane was placed between two electrodes. Then, the solution active resistance $\left(R_{\mathrm{S}}\right)$ was calculated from the obtained experimental data, and the difference with the real part of impedance did not exceed more than $0.25 \%$. The imaginary part of impedance $\left(\operatorname{Im} \mathrm{Z}_{\mathrm{s}}\right)$ was calculated by using the following equation:

$$
\operatorname{Im} Z_{s}=\frac{2 \pi f C_{s} R_{s}^{2}}{1+(2 \pi f)^{2} C_{s}^{2} R_{S}^{2}}=R e Z_{s} \tan \varphi_{s}
$$

The real part of impedance $\left(\operatorname{Re} \mathrm{Z}_{\mathrm{o}}\right)$, phase shift $\left(\varphi_{\mathrm{o}}\right)$ and capacity $\left(C_{\mathrm{o}}\right)$ for overall system consisting of the corresponding solution and membrane can be expressed as:

$$
\begin{gathered}
R e Z_{o}=R e Z_{s}+\frac{R_{m}}{1+(2 \pi f)^{2} C_{m}^{2} R_{m}^{2}} \\
R e Z_{o} \tan \varphi_{o}=I m Z_{s}+\frac{2 \pi f C_{m} R_{m}^{2}}{1+(2 \pi f)^{2} C_{m}^{2} R_{m}^{2}}
\end{gathered}
$$

By measuring these parameters $\left(\operatorname{Re} \mathrm{Z}_{\mathrm{o}} ; \varphi_{\mathrm{o}} ; \mathrm{C}_{\mathrm{o}}\right)$, it was possible to calculate the active membrane resistance $\left(R_{m}\right)$ :

$$
R_{m}=\frac{\left(R e Z_{o} \tan \varphi_{o}-I m Z_{S}\right)^{2}+\left(R e Z_{o}-R e Z_{S}\right)^{2}}{\operatorname{Re} Z_{o}-\operatorname{Re} Z_{S}}
$$

Complementary measurements were carried out with a SurPASS electrokinetic analyzer (Anton Paar $\mathrm{GmbH}$ ) using the lateral method recently proposed by Sedkaoui et al. [29]. Briefly, measurements were conducted with the SurPASS adjustable-gap cell inside which two identical 
membrane samples (dimensions $L \times W: 2 \times 1 \mathrm{~cm}$ ) faced each other, thus forming a channel which was filled with the measuring solution. The cell was surrounded by two cylindrical $\mathrm{Ag} / \mathrm{AgCl}$ electrodes (surface area: $10 \mathrm{~cm}^{2}$ ) through which the measuring solution could flow (further details provided in [29]) until steady-state was reached. From the electrical point of view, the SurPASS adjustable-gap cell consists of the following parallel circuit: membrane / solution-filled channel/membrane. The electrical conductance of the adjustable-gap cell $\left(\mathrm{G}_{\text {cell }}\right)$ can then be written as the sum of the conductance of the channel-filling solution and twice the membrane conductance $\left(\mathrm{G}_{\mathrm{m}}\right)$ :

$$
G_{c e l l}=\frac{W \kappa_{c h}}{L} h_{c h}+2 G_{m}
$$

with $W$ and $L$ the width and the length of the membrane samples, respectively, $h_{c h}$ the distance between the two membrane samples in the measuring cell, $\kappa_{\mathrm{ch}}$ the electrical conductivity of the channel-filling solution

In this work, a series of cell conductance measurements were performed by varying $\mathrm{h}_{\mathrm{ch}}$ (by means of micrometric screws [29]), and $G_{m}$ could be assessed by extrapolating data for $h_{c h}=0$ as shown by Eq. (2). All measurements were performed at room temperature.

\subsection{Filtration experiments}

The filtration of water-alcohol mixtures was carried out at room temperature and transmembrane pressure of 30 bar in the dead-end filtration cells and described in detail elsewhere [11]. For each feed composition, the flux was measured until reaching its steady-state values or to experimentally confirm barrier properties of the membrane. In case of low fluxes or absence of liquid flux, the chamber above the membrane was kept under operating pressure overnight up to 5 days or till enough statistics of liquid flux was measured. Transport characteristics of membranes were expressed in terms of permeability coefficient calculated as:

$$
P=\frac{J \cdot l}{\Delta p}=\frac{V \cdot l}{S \cdot t \cdot \Delta p},
$$

where $V$-permeate volume, $l$ - membrane thickness, $S$ - membranes surface area, $t$ - a time of permeate collection, $\Delta p$ - transmembrane pressure difference. If no flux or low flux was expected, the permeate side of the filtration cell was filled with the corresponded feed solution to increase the sensitivity of determination of liquid permeation through the membrane.

\subsection{Sorption measurements}

For sorption measurements, dense membranes were initially weighed and then soaked in the selected liquid at least 24 hours to guarantee reaching equilibrium. The samples were further 
taken out from the solution, and the excess of solvent at membrane surfaces was removed by placing the membrane between to sheets of filter paper for less than 5 seconds. After removal of the excess of solvent from the surface, the membrane weight $(\mathrm{w})$ was immediately measured in order to prevent desorption of liquid from the sample. The sorption $\mathrm{S}(\mathrm{g} / \mathrm{g})$ was calculated as follows:

$$
S=\frac{w-w_{0}}{w_{0}},
$$

where the subscript 0 refers to the initial weight measured before soaking.

\section{Results and Discussion}

The dry samples were installed into the cell (see Figure 1), and then the water containing $\mathrm{NaCl}$ was placed in two chambers from both sides of the membrane, and then the change of alternating current was measured in time at the frequency of $1000 \mathrm{~Hz}$. Once the steady-state values of current were reached, the frequency was varied in the range of $25-100000 \mathrm{~Hz}$ with the recording of the real part of impedance $\left(\operatorname{Re} \mathrm{Z}_{\mathrm{o}}\right)$, phase shift $\left(\varphi_{\mathrm{o}}\right)$ and capacity $\left(\mathrm{C}_{\mathrm{o}}\right)$. Then, the water was replaced by the aqueous ethanol solution, and the experimental routine was repeated. In this manner, the ethanol concentration was increased from 0 up to $96 \%$. Then the ethanol concentration was decreased to 0 in the same manner, and the experiment was repeated with the same membrane without membrane drying. In all experiments, the composition of the solutions from both sides of the membrane was identical to avoid the diffusion transport through the membrane due to the possible concentration gradient. The real part of impedance $\left(R e \mathrm{Z}_{\mathrm{s}}\right)$, phase shift $\left(\varphi_{\mathrm{s}}\right)$ and capacity $\left(C_{\mathrm{s}}\right)$ of the solution were measured for different samples of the same composition, and the typical results are provided on Figures A-1, A-2, and A-3 in Appendix A.

Figure 3 represents some typical experimental results on the changing of the electric current in time at different water/ethanol compositions. As can be seen, the system reached its equilibrium within 4 hours or less once the composition of the liquid phase was changed. Indeed, the water is non-wetting liquid for these hydrophobic polymers, and no change in electric current in time was observed. The difference in electric current through the system with water in the beginning and the end of series of experiments did not exceed experimental errors of current measures. However, the addition of ethanol in water increases the affinity of the liquid towards the materials like PTMSP and PMP, and hence increases their fractional accessible volume for the solvent molecules that can be accommodated within the polymer. The greater values of the electric conductivity of PTMSP can be explained by almost double fractional accessible volume comparing with PMP $\left(F A V_{\mathrm{PTMSP}}=30 \%, F A V_{\mathrm{PMP}}=16 \%\right)$ in accordance with recently estimated values by using of water-ethanol system [10]. There is a clear observation that the decrease of 
the water in the mixture was accompanied with the increase of the electric current in the system. Figure 3 illustrates the hysteresis effect in the interactions of PMP and PTMSP with the liquid phase since the steady state values obtained were different once the liquid composition was stepwise changed from water to ethanol or vice versa (see both data "W-E" and "E-W" for $60 \%$ on Figure 3).
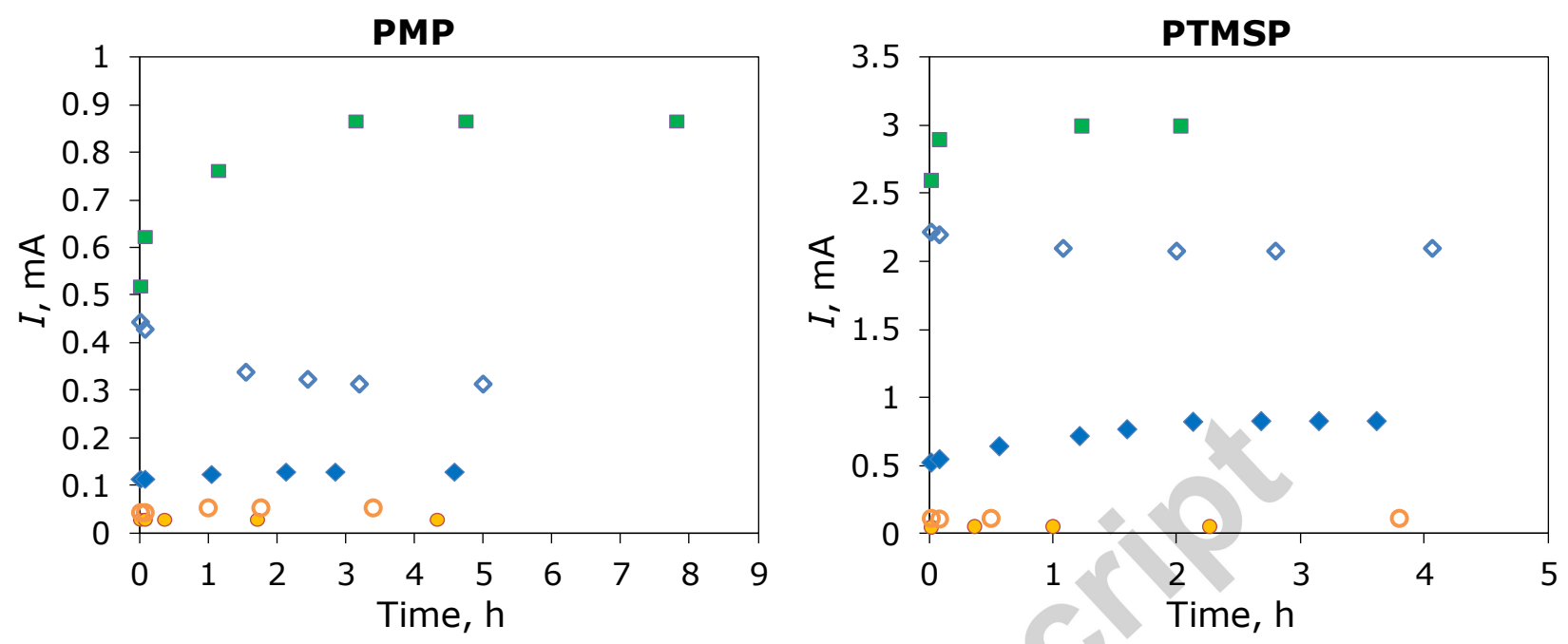

Fig 3. The change of the AC through system over the time (with PMP and PTMSP membrane) with different liquids at $1000 \mathrm{~Hz}\left(C_{\mathrm{NaCl}}=0.5 \mathrm{~g} / \mathrm{L}\right)$; - - ethanol; $\diamond-60 \%$ ethanol (WE); $-60 \%$ ethanol (E-W); • - water (initial); ० - water (after ethanol).

The presence of sodium chloride at $0.5 \mathrm{~g} / \mathrm{L}$ in all solutions allowed increasing the electrical conductivity of the liquid phase despite the different ratio of water/ethanol. Thus, it was possible to significantly highlight the contribution of the polymeric film over the liquid phase. The impedance of all water-ethanol solutions contained $\mathrm{NaCl}$ between electrodes was about $0.5-2 \mathrm{k} \Omega$ and did not significantly vary (see Figure A-1). It also not depends on frequency in contrast to the impedance of overall system with the membrane which decreases at frequencies higher than $1 \mathrm{kHz}$ (see Figure A-4 and A-7). Obtained frequency dependences for real part of impedance have same profile as for modified Nafion membrane [38]. The membrane resistances were calculated using Eq. (5) at different frequencies and then extrapolated to the zero frequency, and these values were higher for more than 3-4 orders of magnitude comparing the corresponded values for the surrounding solution. The resistance of about $1000 \mathrm{k} \Omega$ was observed in the case of high water concentration (see Table 1), which is a non-wetting liquid for these hydrophobic polymers $[10,11]$. The lowest values were observed for ethanol, about $1.0 \mathrm{k} \Omega$ for PMP and 0.15 $\mathrm{k} \Omega$ for PTMSP (see Table 1), which is a wetting liquid for these polymers. As can be seen from Table 1, with the liquid uptake greater than $0.4 \mathrm{~g} / \mathrm{g}$ (PMP: $S=0.42 \mathrm{~g} / \mathrm{g}$ at $90 \mathrm{wt} . \%$; PTMSP: $S=0.46 \mathrm{~g} / \mathrm{g}$ at $40 \mathrm{wt} . \%$ ), the swollen membrane with the thickness of 30-40 $\mu \mathrm{m}$ possessed lower resistance than the corresponded solution between two electrodes $(70 \mathrm{~mm})$. 
It is interesting to notice that the electrical resistance data reflected the hysteresis behavior in the interactions of PMP and PTMSP with the water-ethanol mixtures once the composition was stepwise changed from water to ethanol and back to water (see sorption $S$ and permeability coefficient $P$ for "W-E" and "E-W" in Table 1). PMP and PTMSP are glassy polymers with the glass-transition temperature above $300^{\circ} \mathrm{C}$; therefore, hindering of macrochains rearrangements during the sorption and desorption process can be expected due to the rigid structure of these polymers. Furthermore, it can be noticed that the residual solvent remained in PMP $(0.06 \mathrm{~g} / \mathrm{g})$ and PTMSP $(0.05 \mathrm{~g} / \mathrm{g})$ even after long-term soaking in the distilled water resulted in the drop of membrane resistance in water for 58 and 32\%, respectively (see resistance $R$ at $0 \%$ ethanol content in water for "W-E" and "E-W" in Table 1).

Table 1. Transport and sorption properties of PMP and PTMSP films in water/ethanol: liquid permeability coefficient $P$, membrane resistance $R_{m}$ and sorption $S$ ("W-E" - the liquid composition was stepwise changed from water to ethanol; "E-W" - from ethanol to water, respectively).

\begin{tabular}{|c|c|c|c|c|c|c|c|c|c|c|c|c|}
\hline \multirow{3}{*}{$\begin{array}{c}\text { Ethanol } \\
\text { content, } \\
\text { wt.\% }\end{array}$} & \multicolumn{6}{|c|}{ PMP } & \multicolumn{6}{|c|}{ PTMSP } \\
\hline & \multicolumn{2}{|c|}{$P, 10^{-9} \mathrm{~m}^{2} / \mathrm{h} \cdot \mathrm{bar}$} & \multicolumn{2}{|c|}{$R_{m}, \mathrm{k} \Omega$} & \multicolumn{2}{|c|}{$S, \mathrm{~g} / \mathrm{g}$} & \multicolumn{2}{|c|}{$P, 10^{-9} \mathrm{~m}^{2} / \mathrm{h} \cdot$ bar } & \multicolumn{2}{|c|}{$R_{m}, \mathrm{k} \Omega$} & \multicolumn{2}{|c|}{$S, \mathrm{~g} / \mathrm{g}$} \\
\hline & W-E & E-W & W-E & E-W & W-E & E-Y & W-E & E-W & W-E & E-W & W-E & E-W \\
\hline 0 & 0 & 0 & 910 & 380 & 0 & 0.06 & 0 & 0 & 750 & 510 & 0 & 0.05 \\
\hline 10 & 0 & 0 & 880 & 520 & 0.07 & 0.12 & 0 & 0 & 900 & 580 & 0.14 & 0.20 \\
\hline 20 & 0 & 0.003 & 1030 & 840 & 0.10 & $0.1 S$ & 0 & 0.046 & 880 & 214 & 0.26 & 0.32 \\
\hline 30 & 0.001 & 0.007 & 1010 & 970 & 0.17 & 0.27 & 0 & 0.190 & 740 & 9.0 & 0.36 & 0.42 \\
\hline 40 & 0.004 & 0.043 & 10 & 350 & 0.20 & 0.25 & 0 & 0.416 & 250 & $\begin{array}{l}0.7 \\
4\end{array}$ & 0.46 & 0.55 \\
\hline 50 & 0.004 & 0.061 & 1070 & 28.4 & 0.27 & 0.36 & 0.024 & 0.653 & 52 & 0.44 & 0.55 & 0.64 \\
\hline 60 & 0.007 & 0.102 & 1200 & 11.5 & 0.29 & $0.3 \xi$ & 0.120 & 1.226 & 13.1 & 0.33 & 0.59 & 0.74 \\
\hline 70 & 0.017 & 0.213 & 680 & 4.36 & 0.33 & 0.4 & 0.251 & 1.598 & 2.02 & 0.27 & 0.63 & 0.76 \\
\hline 80 & 0.030 & 0.421 & 51.7 & 2.25 & 0.39 & 0.46 & 0.847 & 2.324 & 0.54 & 0.20 & 0.73 & 0.83 \\
\hline 90 & 0.268 & 0.766 & 2.01 & 1.25 & 0.42 & 0.48 & 1.661 & 2.988 & 0.31 & 0.20 & 0.82 & 0.87 \\
\hline 96 & 1.049 & 1.049 & 1.18 & 1.18 & 0.53 & 0.5 & 3.724 & 3.724 & 0.15 & 0.15 & 0.95 & 0.95 \\
\hline
\end{tabular}

The analysis of the results for overall capacity indicated that the membrane acted as a capacitor at low ethanol concentrations. As can be seen from Figure 4, there is a common trend in the change of the overall capacity at lower ethanol concentrations regardless the frequencies. The more pronounced difference can be found later at higher alcohol content. Besides, all curves 
demonstrated the maximum, which can be attributed to the appearance of the transport channels where cooperative diffusion or convection can be realized. It is in good agreement with results obtained in [44] for these polymers in ethanol where it was demonstrated the influence of coupling effects on transport. It is interesting to notice that the capacity results also revealed the hysteresis effect observed earlier with the resistance. The transition from a conductor with diffusion effect into capacitor takes place at a lower concentration of ethanol than the transition from the capacitor to conductor at increasing ethanol concentration. This result confirms the appearance of percolation cluster in membranes at high ethanol concentration.
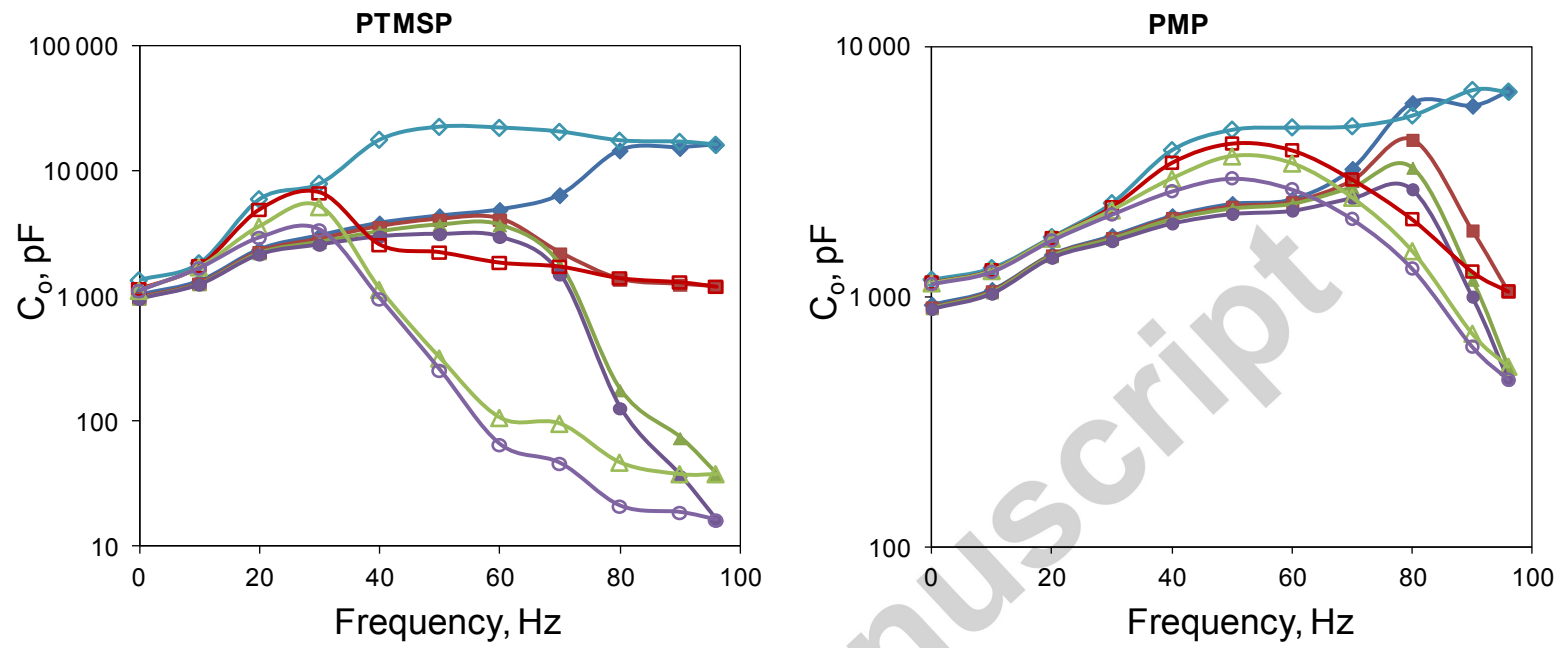

Fig 4. Capacity of system at different ethanol concentrations: $\bullet-$ at $25 \mathrm{~Hz}$ (W-E); $\diamond-$ at $25 \mathrm{~Hz}(\mathrm{E}-\mathrm{W}) ; \boldsymbol{-}$ - at $100 \mathrm{~Hz}(\mathrm{~W}-\mathrm{E}) ; \square-$ at $100 \mathrm{~Hz}(\mathrm{E}-\mathrm{W}) ; \boldsymbol{\Delta}$ - at $1000 \mathrm{~Hz}$ (W-E); $\Delta$ - at $1000 \mathrm{~Hz}$ $(\mathrm{E}-\mathrm{W}) ; \bullet-$ at $10000 \mathrm{~Hz}(\mathrm{~W}-\mathrm{E}) ;$ ○ - at $10000 \mathrm{~Hz}(\mathrm{E}-\mathrm{W})$;

Since calculated resistance consists not only membrane resistance itself but also secondary effects on membrane surface to diminish their influence membrane resistance was obtained by fitting of results from eq. (5) at different frequencies into zero frequency. Figure 5 shows the comparison between the results provided by permeability coefficient and electrical resistance calculated from eq. (5) for both membranes. In order to make the comparison easier, results obtained with a given water/ethanol mixture were normalized with respect to those obtained with ethanol (96\%). All membrane permeabilities were obtained in steady state regime when permeability was stable during at least several hours. A very good agreement was obtained between the normalized permeability coefficient, $P / P_{\mathrm{EtOH}}$, and the reverse normalized electrical resistance, $R_{m \mathrm{EtOH}} / R_{m}$ (the reverse ratio was considered for the electrical resistance since this latter was the highest when measured in pure water). This finding demonstrates that (i) both liquid transport and electrical conductance occurred through the same transport channels within 
the membranes, and (ii) the electricaFresistance method can highlight the formation of such (pseudo) liquid channels (percolation clusters) through polymers of intrinsic microporosity.
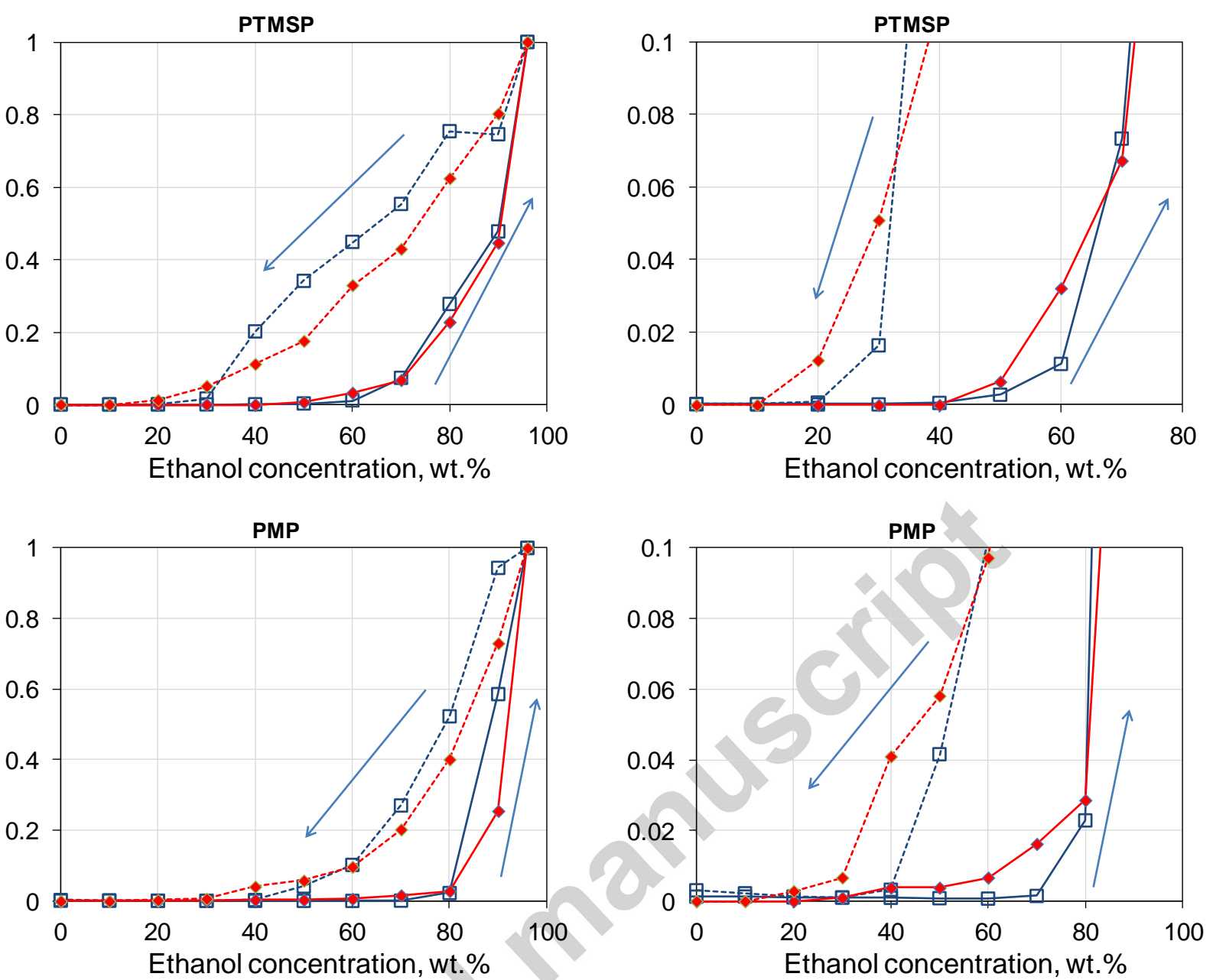

Fig 5. Relative liquid permeability coefficient $P / P_{\mathrm{EtOH}}(\bullet)$ and resistance $R_{m \mathrm{EtOH}} / R_{m}(\square)$ as a function of liquid composition.

From results depicted in Figure 5, it appears that no percolation clusters are formed through PTMSP and PMP membranes for ethanol concentrations up to about 50 and $70 \mathrm{wt}$ \%, respectively. Beyond these threshold values, the increase in the ethanol concentration is accompanied by a substantial increase in the liquid transport as well as in the reverse normalized electrical resistance, which is attributed to the formation of percolation clusters through the membrane matrix (schematic illustration can be found on Figure 6). 


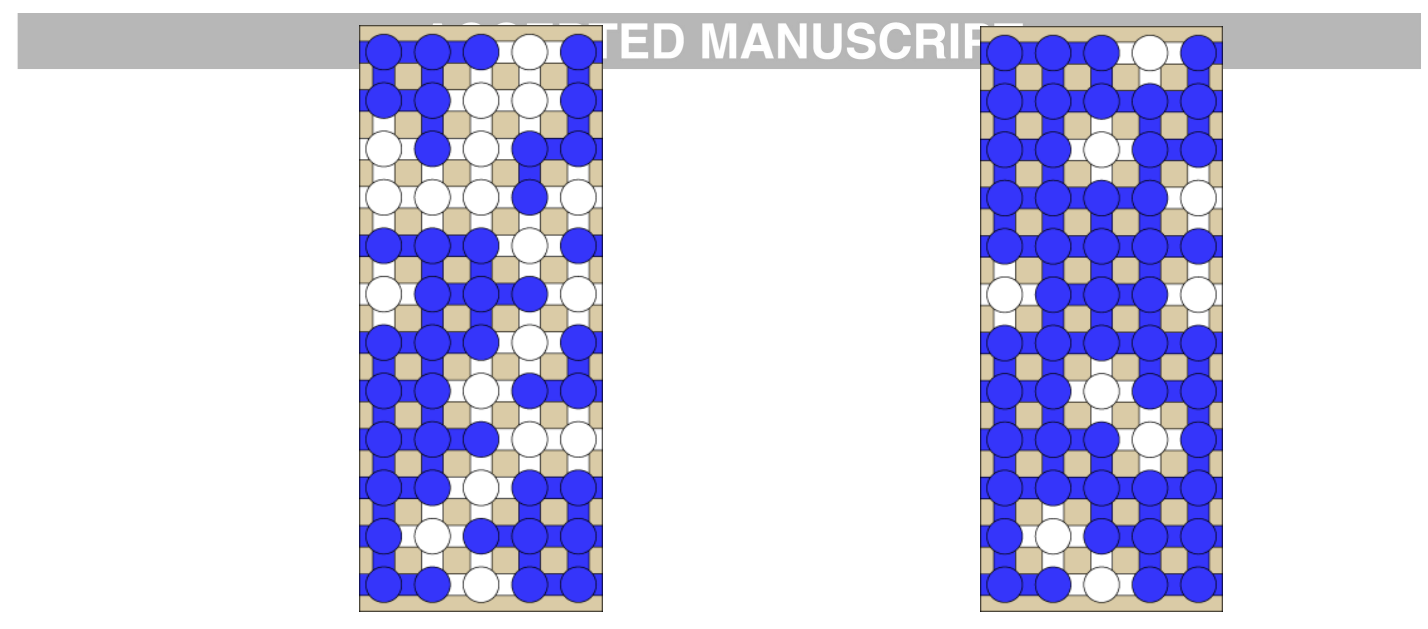

Fig 6. Schematic illustration of the polymeric matrix before (left) and after (right) percolation clusters formation.

Unlike permeability coefficient and electrical resistance measurements, sorption experiments revealed no threshold behavior with the ethanol content, and a noticeable amount of liquid was found to enter both PTMSP and PMP membranes as soon as ethanol (wetting liquid) was added to the liquid phase (see Table 1). The sorption was measured for both types of waterethanol solutions with and without of the $\mathrm{NaCl}$, and comparison of these experiments indicates no influence of $\mathrm{NaCl}$ on the sorption of the liquids. The above results (Figure 5 and Table 1) therefore indicate that below a critical ethanol concentration (about 50 and 70 wt. \% for PTMSP and PMP membranes, respectively), the solution can enter the membrane ( $S=0.55$ and $0.33 \mathrm{~g} / \mathrm{g}$ for the critical ethanol concentrations with PTMSP and PMP membranes, respectively), thus forming small liquid clusters but these latter are not connected with each other. As a result, membrane permeability is low or not detectable, and the membrane behaves mostly as a capacitor, i.e., storing charges inside non-connected clusters. The difference in sorption at critical ethanol concentrations between two polymers likely connected with individual features of polymer structures. This emphasizes that static (e.g., sorption) and dynamic (e.g., filtration) experiments might not always be comparable and complimentary for prediction analysis. For investigated polymers, at low ethanol concentrations, only low flux through the membrane is possible by solution-diffusion mechanism till percolation cluster is formed at a high concentration of ethanol. Such cluster posses much higher flux through the membrane.

The liquid permeability coefficient and electrical resistance measurements both result from dynamic processes, and, hence, the electrical resistance technique can be used to predict liquid transport. Notably, it could be possible to determine the membrane permeability coefficient for any water/ethanol mixture from the measurement of the relative resistance $\left(R_{m \mathrm{EtOH}} / R_{m}\right)$ provided the permeability in the wetting solution $\left(P_{\mathrm{EtOH}}\right)$ is known. Since the time required for electrical 
resistance measurements is mainly determined by the sorption process, this technique is likely to provide significant time reduction when investigating low permeable or barrier materials. For instance, PMP and PTMSP membranes were kept at a pressure difference of 30 bar during 4-5 days to confirm their barrier properties towards the solutions with low ethanol concentrations (see Table 2). At the same time, 2-8 hours were sufficient to obtain the steady-state values of the electric current flowing through the membranes. This makes electrical resistance measurements as an express technique to identify when the membrane can be operated as the gas-liquid membrane contactor (no liquid permeability) or filtration membrane (permeable for the liquid phase).

Table 2. The time required to obtain stable results in permeability and resistance measurements.

\begin{tabular}{ccc}
\hline Ethanol concentration, wt.\% & Permeability & Electrical resistance \\
\hline 0 & 5 days & $2-5$ hours \\
10 & 5 days & $2-4$ hours \\
20 & $4-5$ days & $2-4$ hours \\
30 & $4-5$ days & $2-4$ hours \\
40 & $4-5$ days & $5-8$ hours \\
50 & $2-4$ days & $3-8$ hours \\
60 & $8-32$ hours & $4-5$ hours \\
70 & $6-8$ hours & $3-7$ hours \\
80 & $5-6$ hours & $5-6$ hours \\
90 & $3-5$ hours & $2-7$ hours \\
96 & $3-4$ hours & $3-4$ hours \\
\hline
\end{tabular}

The above results, performed in the normal mode, i.e., with current lines normally oriented to the membrane surface, were confirmed by lateral measurements widely used for characterization of hydrophilic materials such as ion-exchange membranes. This method was proposed by Sedkaoui et al. [29] and described in section 2.2. Figure 7 shows the variation of the cell conductance measured with the PMP membrane by varying the distance between membrane samples $\left(\mathrm{h}_{\mathrm{ch}}\right)$.According to Eq. (6) the membrane conductance can be inferred by extrapolation at $\mathrm{h}_{\mathrm{ch}}=0$. For measurements performed in water and mixture with $40 \%$ of ethanol, the membrane electrical conductance was found extremely low, but it increased significantly in the 20/80\% water/ethanol mixture, and the highest value was achieved for ethanol. This can be associated with the formation of percolation clusters within the membrane matrix. It is worth stressing, however, that the lateral method developed by Sedkaoui et al. [29] is more suited for highly 
conductive materials (because the celF configuration is in this case equivalent to an electrical circuit with several parallel-connected branches [29]) and have low accuracy for non-conductive materials like investigated polymers in water. Therefore, it can be concluded that the lateral method can be also used with certain limitations for characterization of hydrophobic materials like polymers of intrinsic microporosity.

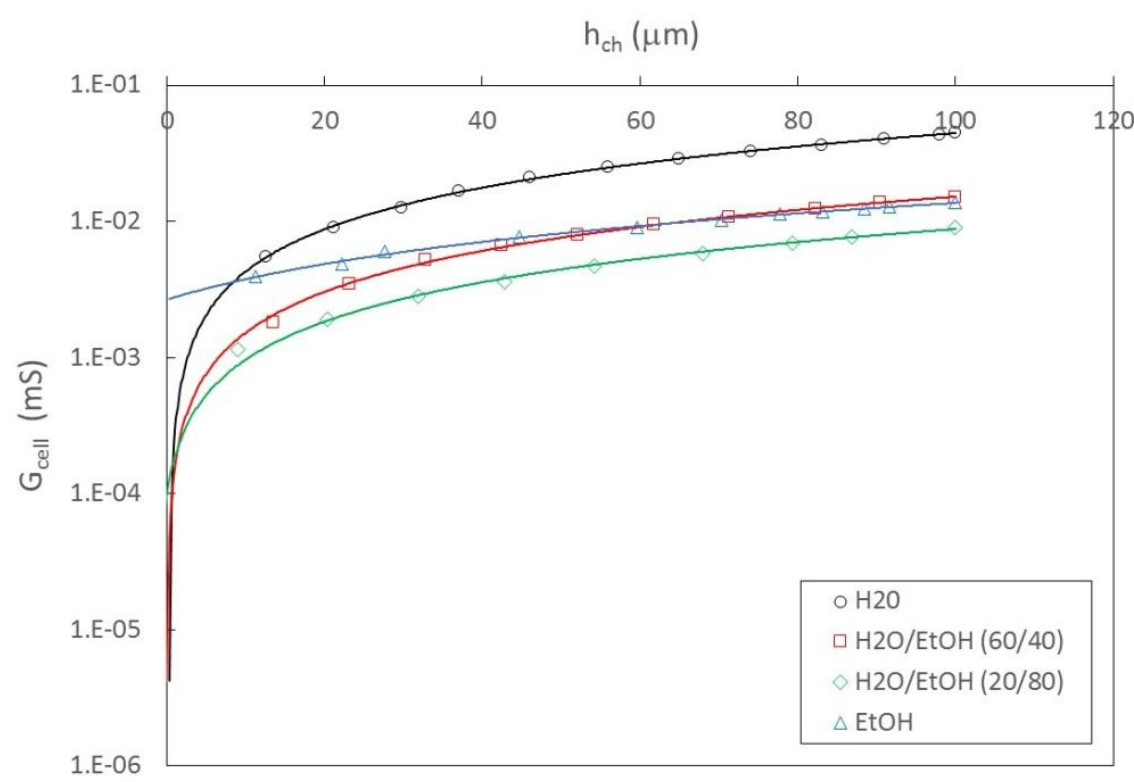

Fig 7. Variation of the cell conductance $\left(\mathrm{G}_{\text {cell }}\right)$ as a function of the gap between membrane samples $\left(\mathrm{h}_{\mathrm{ch}}\right)$ in the lateral-measurement configuration with the PMP membrane.

\section{Conclusion}

It was demonstrated that the membrane electrical resistance method is a very attractive, time effective approach to evaluate barrier or low permeable membrane materials. Indeed, it was shown to be able to highlight the formation of percolation clusters inside membranes made from polymers of intrinsic microporosity (PTMSP and PMP). The analysis of the phase shift between the electrical current and the electrical potential showed that the behavior of PTMSP and PMP membranes changed from mainly capacitive at low ethanol concentrations to the ion conductive as the ethanol concentration was increased.

Sorption experiments indicated liquid uptake by PTMSP and PMP membranes even at low ethanol concentrations. On the other hand, no liquid flux or hardly detectable flux was observed until a critical ethanol concentration in the liquid phase (about 50 and 70 wt. \% for PTMSP and PMP membranes, respectively). These results showed that although liquid clusters were present inside the membrane at low ethanol concentrations, they were not connected with other, thus preventing any significant liquid permeation until the critical ethanol concentration in the liquid phase was reached, which allowed the formation of connected paths and percolation clusters. 
The very good quantitative agreement was found between the relative change of the membrane electrical resistance and the permeability as a function of the ethanol content in the liquid phase. Consequently, electrical resistance measurements could be used as an express method to determine the membrane permeability of low permeable materials since the time required to get stable results was found to be much shorter for electrical resistance measurements than for permeability measurements.

A hysteresis effect was observed for both membrane permeability and resistivity by increasing and decreasing stepwise the ethanol concentrations. This hysteresis demonstrates the influence of the sample history on the membrane characteristics. The good correlation of electric conductivity and permeability of membranes suggests that this effect could be connected with the formation of pore-like transport channels in the polymer since the solution has low resistance and polymer is dielectric. Such transport channels or percolation clusters provide high membrane conductivity and permeability until they are disrupted due to low ethanol concentration.

\section{Acknowledgments}

The authors gratefully acknowledge Sobolev V.D. and Matson S.M. for fruitful discussion and assistance with article preparation. Anthony Szymczyk thanks Campus France and the French embassy in the Russian Federation for financial support through the program André Mazon 2015. This work was carried out within the state program of TIPS RAS supported by FASO Russia.

\section{Appendix A}

Figures A-1, A-2 and A-3 represent experimentally measured data for water-ethanol solutions.

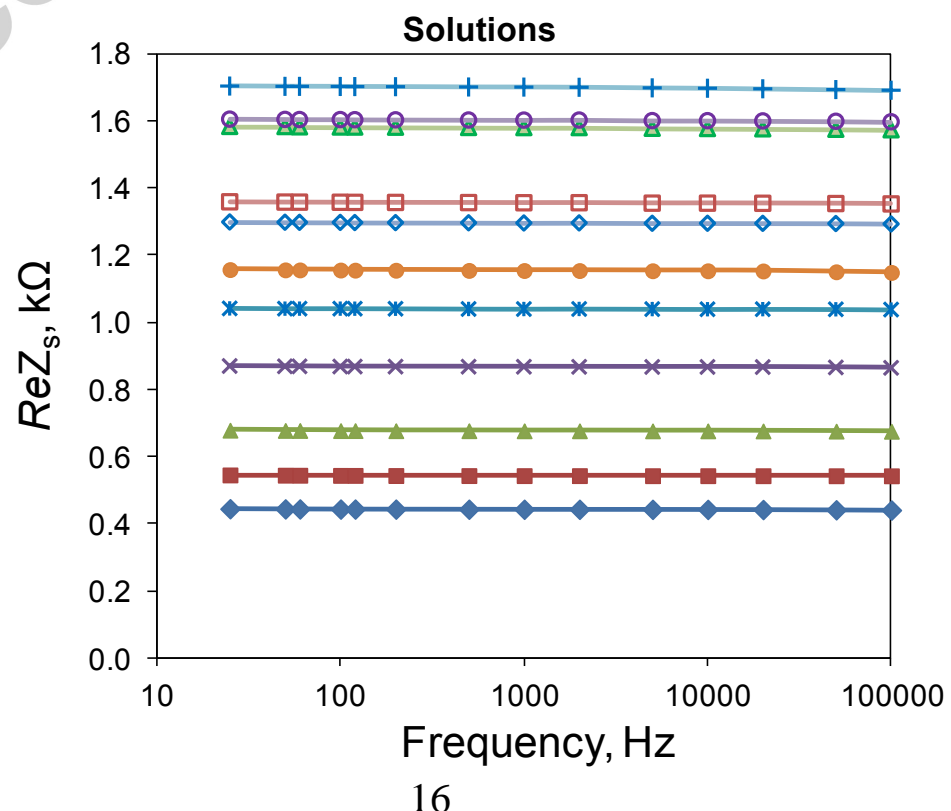


Fig A-1. Experimentally measured real part of impedance of water-ethanol solutions $R_{e} \mathrm{Z}_{\mathrm{s}}$.

- water, $\mathbf{- 1 0 \%}$ ethanol; $\boldsymbol{\Delta}-20 \%$ ethanol; $\times-30 \%$ ethanol; $*-40 \%$ ethanol; $\bullet-50 \%$ ethanol; $\diamond-60 \%$ ethanol; $\square-70 \%$ ethanol; $\Delta-80 \%$ ethanol; $\circ-90 \%$ ethanol; $+-96 \%$ ethanol.

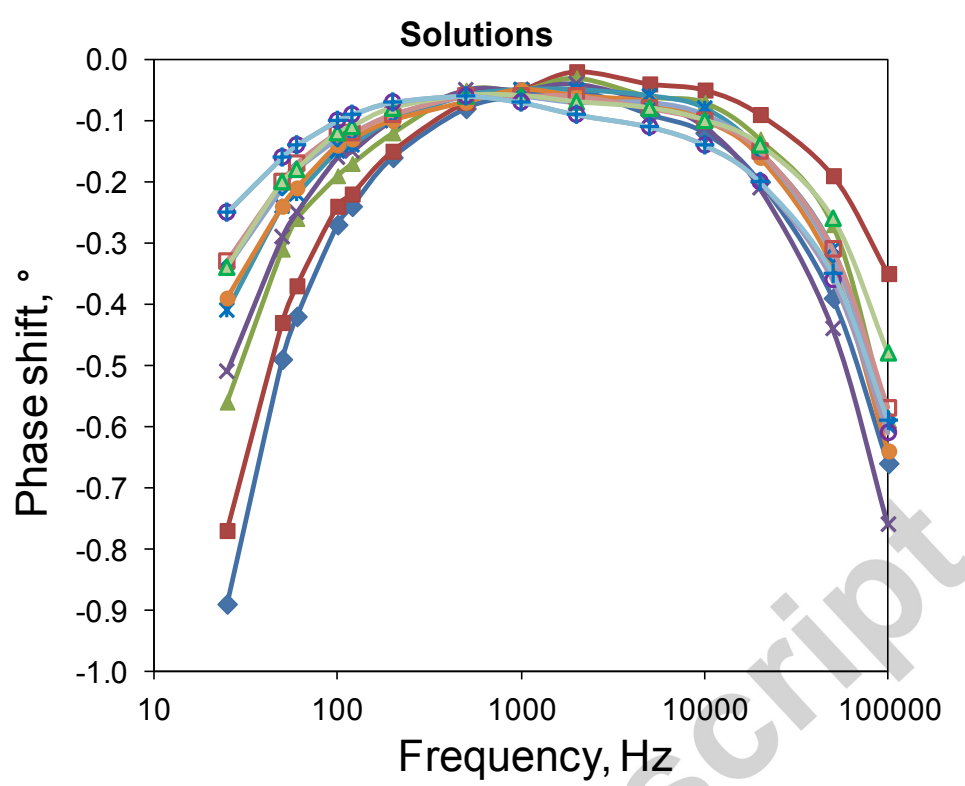

Fig A-2. Experimentally measured phase shift in water-ethanol solutions $\varphi_{\mathrm{s}}$. - water, $10 \%$ ethanol; $\boldsymbol{\Delta}-20 \%$ ethanol; $\times-30 \%$ ethanol; $*-40 \%$ ethanol; $\bullet-50 \%$ ethanol; $\diamond-60 \%$ ethanol; $\square-70 \%$ ethanol; $\Delta-80 \%$ ethanol; $\circ-90 \%$ ethanol; $+-96 \%$ ethanol.

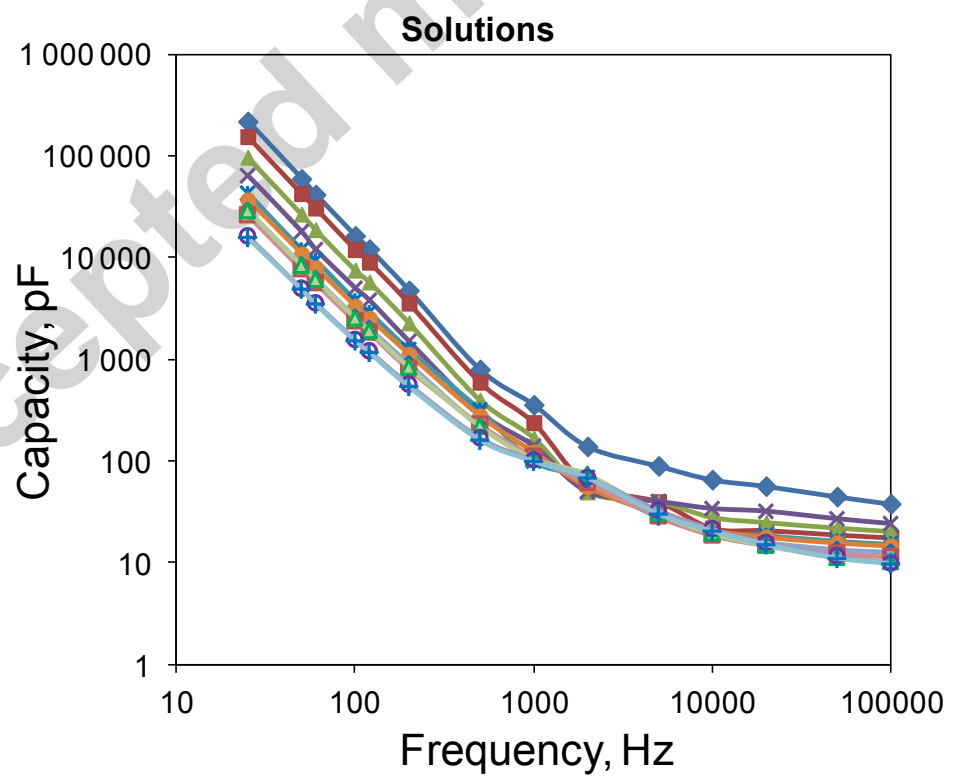

Fig A-3. Experimentally measured capacity of water-ethanol solutions $\mathrm{C}_{\mathrm{s}}$. - water, $10 \%$ ethanol; $\boldsymbol{\Delta}-20 \%$ ethanol; $\times-30 \%$ ethanol; * $-40 \%$ ethanol; $\bullet-50 \%$ ethanol; $\diamond-60 \%$ ethanol; $\square-70 \%$ ethanol; $\Delta-80 \%$ ethanol; $\circ-90 \%$ ethanol; $+-96 \%$ ethanol. 
Figures A-4, A-5 and A- 6 represent experimentally measured data for system consists of PTMSP membrane and water-ethanol solutions. Examples of the results for one membrane sample.
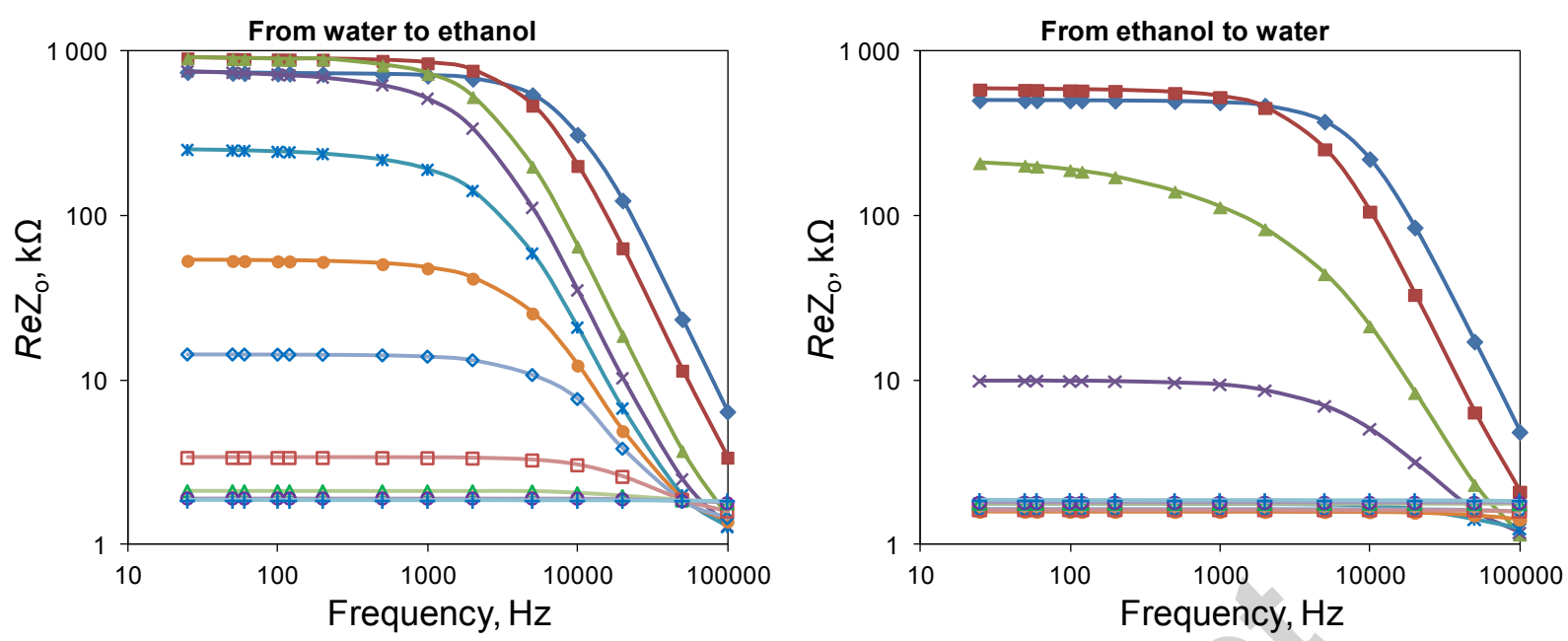

Fig A-4. Experimentally measured real part of impedance of system consists of PTMSP membrane and water-ethanol solutions $\operatorname{Re} \mathrm{Z}_{\mathrm{o}}$. - water, $\boldsymbol{-}-10 \%$ ethanol; $\boldsymbol{\Delta}-20 \%$ ethanol; $\times-$ $30 \%$ ethanol; $*-40 \%$ ethanol; $\bullet-50 \%$ ethanol; $\diamond-60 \%$ ethanol; $\square-70 \%$ ethanol; $\Delta-80 \%$ ethanol; o-90\% ethanol; + - $96 \%$ ethanol.
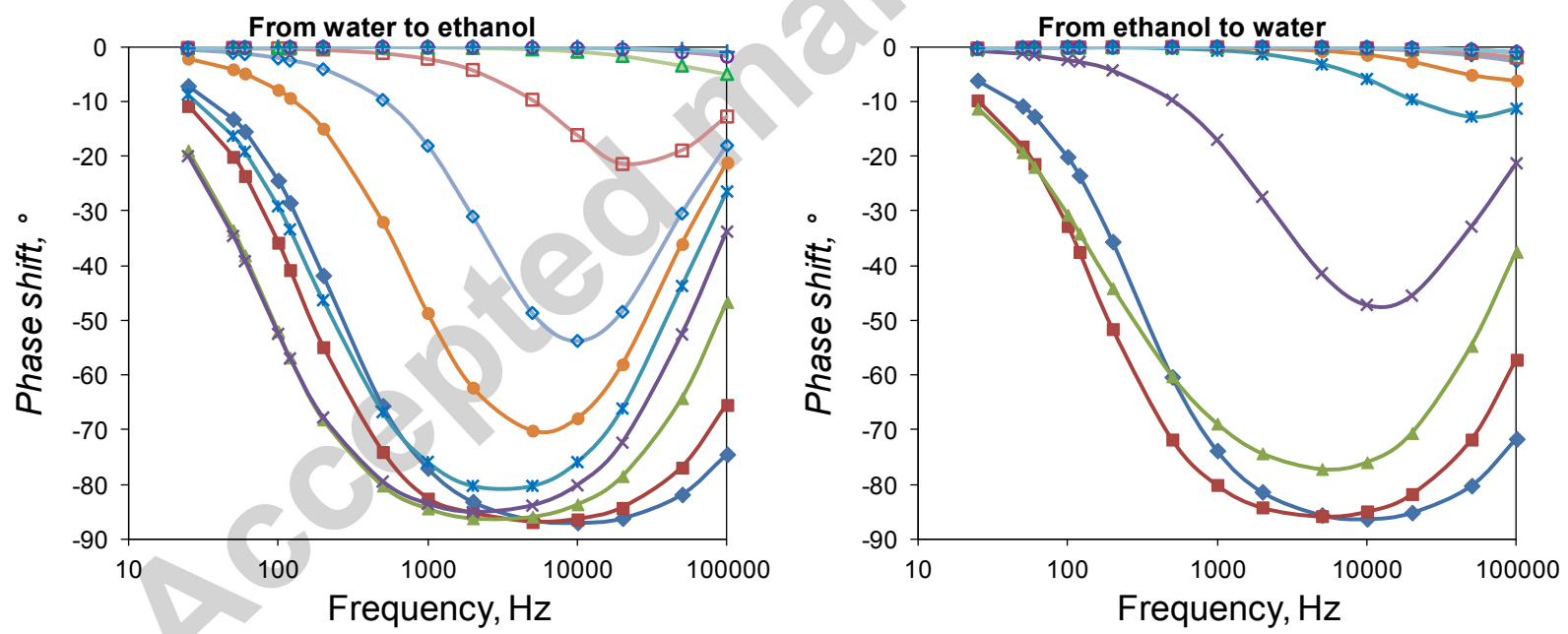

Fig A-5. Experimentally measured phase shift in the system consists of PTMSP membrane and water-ethanol solutions $\varphi_{\mathrm{o}} .-$ water, $\mathbf{- 1 0 \%}$ ethanol; $\boldsymbol{\Delta}-20 \%$ ethanol; $\times-30 \%$ ethanol; $*-40 \%$ ethanol; $\bullet-50 \%$ ethanol; $\diamond-60 \%$ ethanol; $\square-70 \%$ ethanol; $\Delta-80 \%$ ethanol; $\bigcirc-$ $90 \%$ ethanol; $+-96 \%$ ethanol. 

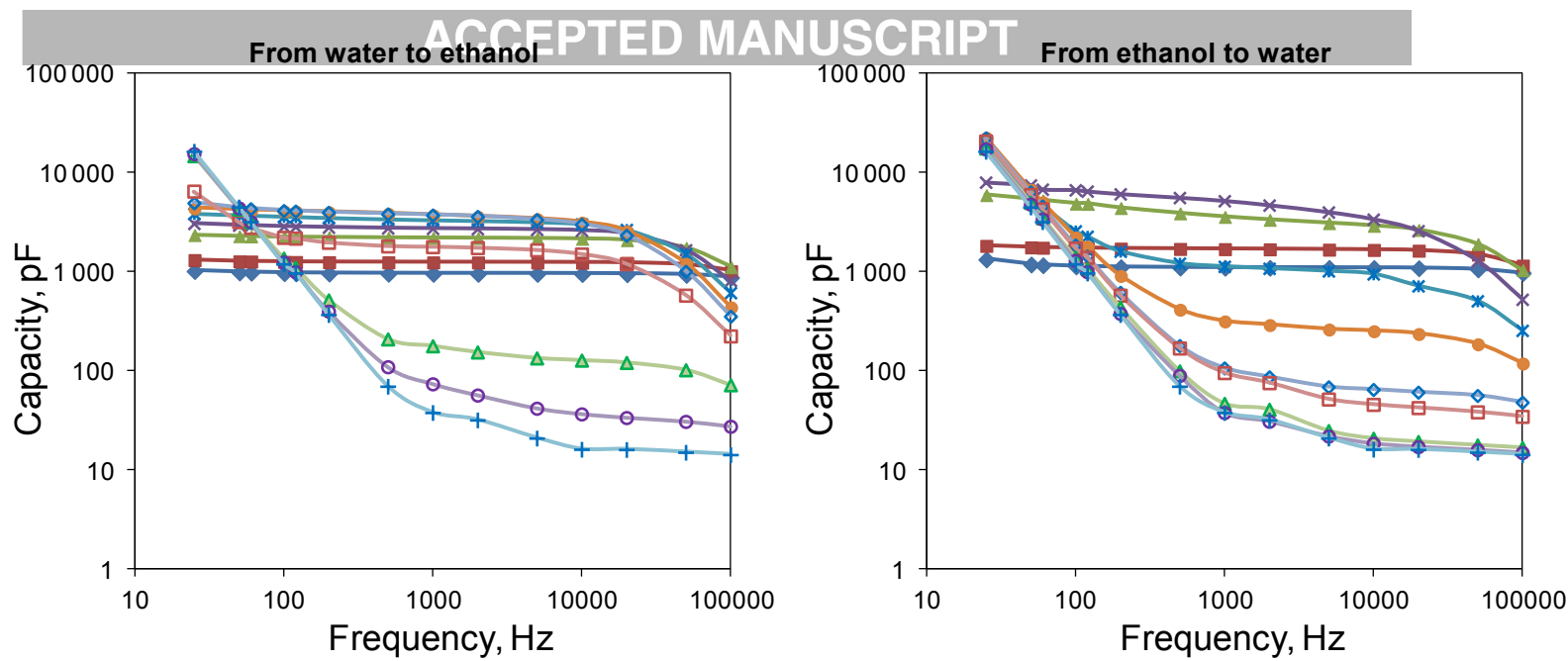

Fig A-6. Experimentally measured capacity in the system consists of PTMSP membrane and water-ethanol solutions $\mathrm{C}_{\mathrm{o}}$. - water, $\mathbf{- 1 0 \%}$ ethanol; $\boldsymbol{\Delta}-20 \%$ ethanol; $\times-30 \%$ ethanol; $*-40 \%$ ethanol; $\bullet-50 \%$ ethanol; $\diamond-60 \%$ ethanol; $\square-70 \%$ ethanol; $\Delta-80 \%$ ethanol; $\circ-$ $90 \%$ ethanol; $+-96 \%$ ethanol.

Figures A-7, A-8 and A-9 represent experimentally measured data for system consists of PMP membrane and water-ethanol solutions. Examples of the results for one membrane sample.
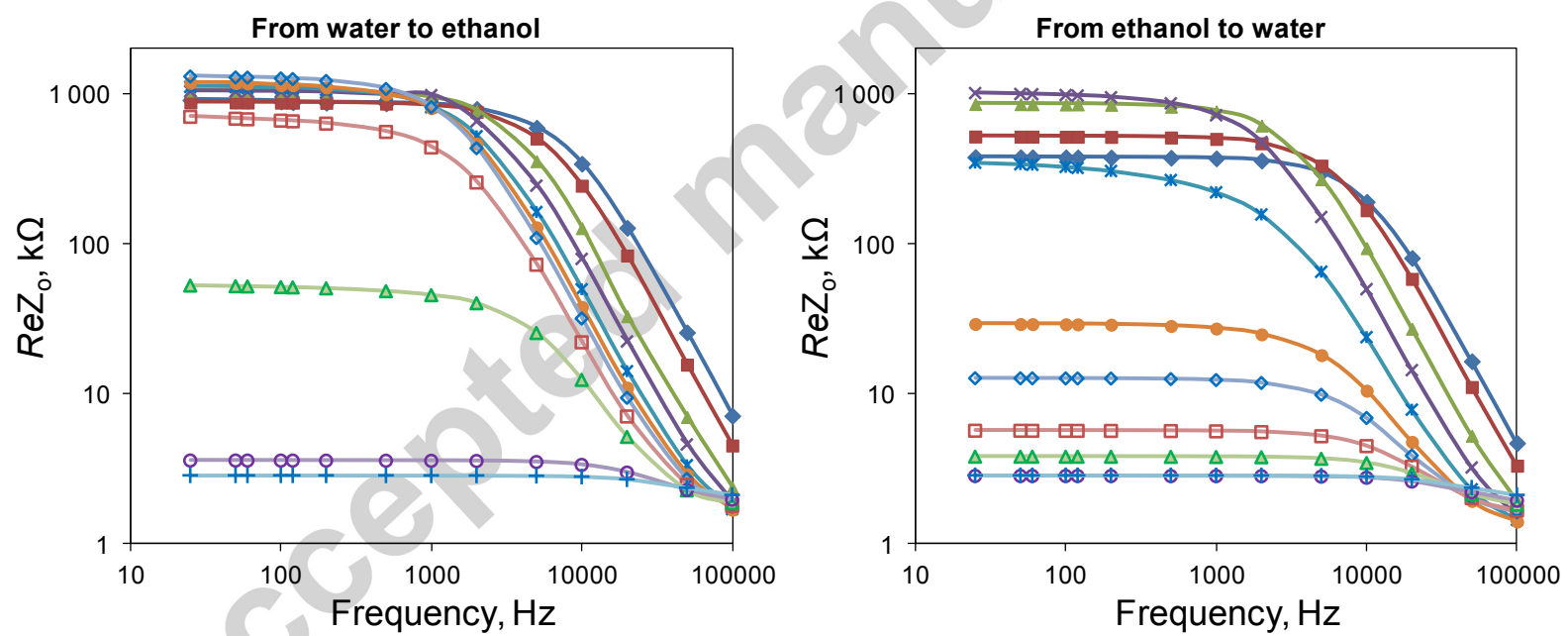

Fig A-7. Experimentally measured real part of impedance of system consists of PMP membrane and water-ethanol solutions $\operatorname{Re} \mathrm{Z}_{\mathrm{o}}$. - water, - $-10 \%$ ethanol; $\boldsymbol{\Delta}-20 \%$ ethanol; $\times-$ $30 \%$ ethanol; $*-40 \%$ ethanol; $\bullet-50 \%$ ethanol; $\diamond-60 \%$ ethanol; $\square-70 \%$ ethanol; $\Delta-80 \%$ ethanol; $\circ-90 \%$ ethanol; + - 96\% ethanol. 

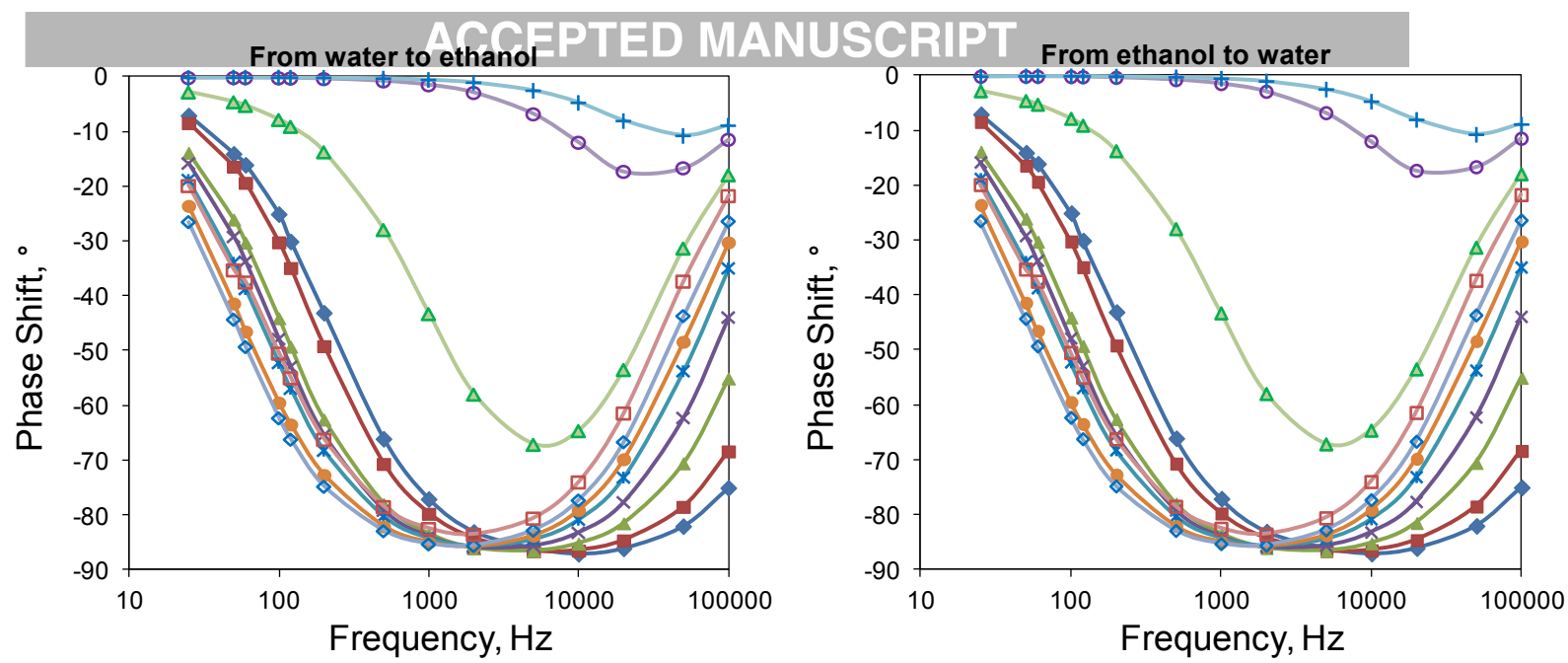

Fig A-8. Experimentally measured phase shift in the system consists of PMP membrane and water-ethanol solutions $\varphi_{\mathrm{o}}$. - water, - $10 \%$ ethanol; $\boldsymbol{\Delta}-20 \%$ ethanol; $\times-30 \%$ ethanol; $*-40 \%$ ethanol; $\bullet-50 \%$ ethanol; $\diamond-60 \%$ ethanol; $\square-70 \%$ ethanol; $\Delta-80 \%$ ethanol; $\circ-$ $90 \%$ ethanol; $+-96 \%$ ethanol.
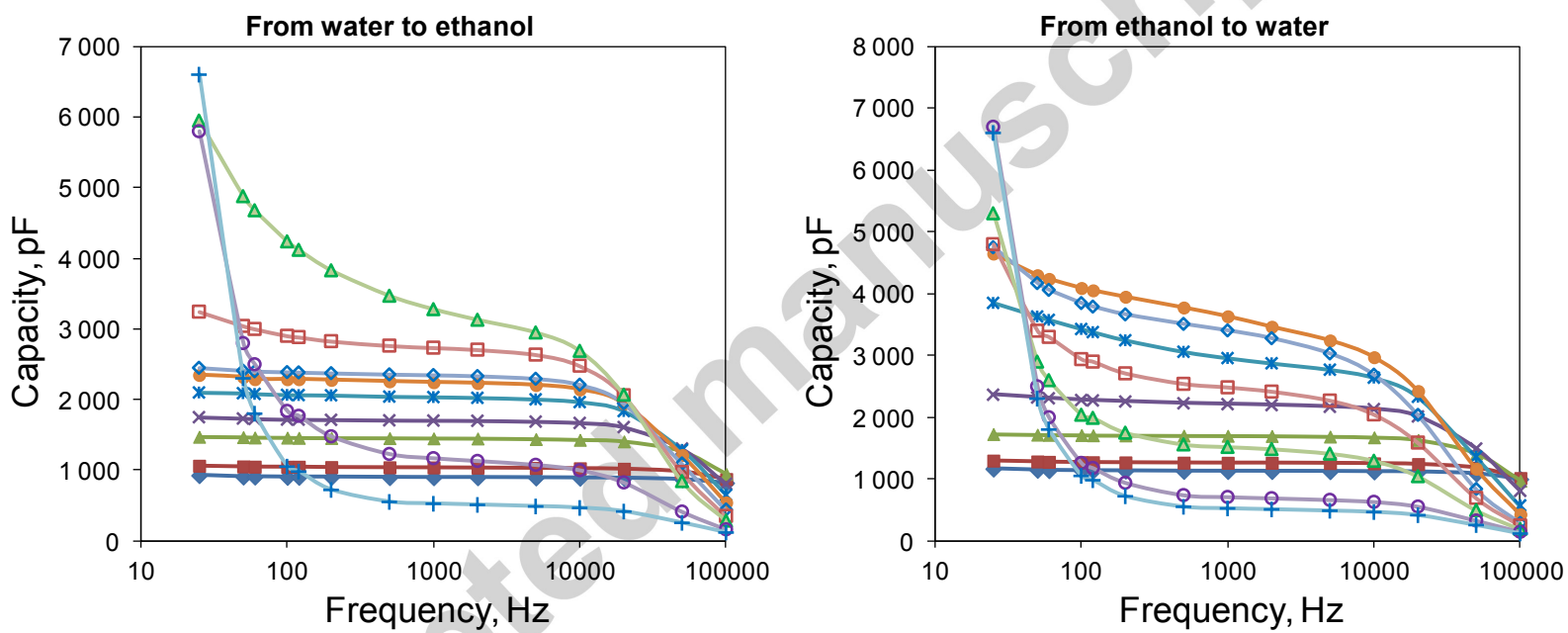

Fig A-9. Experimentally measured capacity in the system consists of PMP membrane and water-ethanol solutions $\mathrm{C}_{\mathrm{o}}$. - water, - $-10 \%$ ethanol; $\boldsymbol{\Delta}-20 \%$ ethanol; $\times-30 \%$ ethanol; * $40 \%$ ethanol; $\bullet-50 \%$ ethanol; $\diamond-60 \%$ ethanol; $\square-70 \%$ ethanol; $\Delta-80 \%$ ethanol; $\bigcirc-90 \%$ ethanol; +-96\% ethanol.

\section{References}

1. R.W.Baker. Membrane technology. John Wiley \& Sons, Inc., 2012.

2. S.P.Nunes, K.-V.Peinemann, eds. Membrane technology: in the chemical industry. John Wiley \& Sons, 2006.

3. E.Curcio, E.Drioli. Membrane distillation and related operations-a review. Separation and Purification Reviews, 34 (2005) 35. 
4. G.Kang, Y.Cao. Application and modification of poly(vinylidene fluoride) (PVDF) membranes-A review. J. Membr. Sci., 463 (2014) 145.

5. A.Mansourizadeh, A.F.Ismail. Hollow fiber gas-liquid membrane contactors for acid gas capture: a review. Journal of Hazardous Materials, 171 (2009) 38.

6. D.A.Zaidiza, S. G.Wilson, B.Belaissaoui, S.Rode, C.Castel, D.Roizard, E.Favre . Rigorous modelling of adiabatic multicomponent CO 2 post-combustion capture using hollow fibre membrane contactors. Chemical Engineering Science, 145 (2016) 45.

7. A.V.Volkov, G.A.Korneeva, G.F.Tereshchenko. Organic solvent nanofiltration: prospects and application. Russ. Chem. Rev., 77 (2008) 983.

8. P.Marchetti, M.F.Jimenez Solomon, G.Szekely, A.G.Livingston. Molecular separation with organic solvent nanofiltration: a critical review. Chemical reviews, 114 (2014) 10735.

9. A.Grekhov, A.Belogorlov, A.Yushkin, A.Volkov. New express dynamic technique for liquid permeation measurements in a wide range of trans-membrane pressures. J. Membr. Sci., 390-391 (2012) 160.

10. A.Yushkin, A.Grekhov, S.Matson, M.Bermeshev, V.Khotimsky, E.Finkelstein, P.M.Budd, V.Volkov, T.J.H.Vlugt, A.Volkov. Study of glassy polymers fractional accessible volume (FAV) by extended method of hydrostatic weighing: Effect of porous structure on liquid transport. React. Funct. Polym., 86 (2015) 269.

11. A.Volkov, A.Yushkin, A.Grekhov, A.Shutova, S.Bazhenov, S.Tsarkov, V.Khotimsky, T.J.H.Vlugt, V.Volkov. Liquid permeation through PTMSP: One polymer for two different membrane applications. J. Membr. Sci., 440 (2013) 98.

12. J.W.Essam. Percolation theory. Reports on Progress in Physics, 43 (1980) 833

13. M.Parlar, Y.C.Yortsos. Percolation theory of vapor adsorption-desorption processes in porous materials. J. Colloid Interface Sci., 124 (1988) 162.

14. H.E.Stanley, J.S.Andrade, S.Havlin, H.A.Makse, B.Suki. Percolation phenomena: a broadbrush introduction with some recent applications to porous media, liquid water, and city growth. Physica A: Statistical Mechanics and its Applications, 266 (1999) 5.

15. W.Bauhofer, J.Z.Kovacs. A review and analysis of electrical percolation in carbon nanotube polymer composites. Composites Science and Technology, 69 (2009) 1486.

16. D.Fangming, J.E.Fischer, K.I.Winey. Effect of nanotube alignment on percolation conductivity in carbon nanotube/polymer composites. Phys. Rev. B, 72 (2005) 121404.

17. A.M.Grekhov, Y.S.Eremin. On the threshold concentration of sticks providing formation of a percolating cluster in mixed matrix membranes. J. Membr. Sci., 485 (2015) 42. 
18. J.G.Meier, C.Crespo, J.L.Pelegay, P.Castell, R.Sainz, W.K.Maser, A.M.Benito. Processing dependency of percolation threshold of MWCNTs in a thermoplastic elastomeric block copolymer. Polymer, 52 (2011) 1788.

19. M.Crespo, N.Méndez, M.Gonzalez, J.Baselga, J.Pozuelo. Synergistic effect of magnetite nanoparticles and carbon nanofibres in electromagnetic absorbing composites. Carbon, $\mathbf{7 4}$ (2014) 63.

20. B.Malmgren-Hansen, T. S.Sørensen, J.B.Jensen, M.Hennenberg. Electric impedance of cellulose acetate membranes and a composite membrane at different salt concentrations. $J$. Colloid Interface Sci., 130 (1989) 359.

21. K.Asaka. Dielectric properties of cellulose acetate reverse osmosis membranes in aqueous salt solutions. J. Membr. Sci., 50 (1990) 71.

22. A.Canas, M.J.Ariza, J.Benavente. Characterization of active and porous sublayers of a composite reverse osmosis membrane by impedance spectroscopy, streaming and membrane potentials, salt diffusion and X-ray photo-electron spectroscopy measurements. J. Membr. Sci., 183 (2001) 135.

23. J.S.Park, J.H.Choi, J.J.Woo, S.H.Moon. An electrical impedance spectroscopic (EIS) study on transport characteristics of ion-exchange membrane systems. J. Colloid Interface Sci., 300 (2006) 655.

24. H.G.L.Coster, K.J.Kim, K.Dahlan, J.R.Smith, C.J.D.Fell. Characterisation of ultrafiltration membranes by impedance spectroscopy. I. Determination of the separate electrical parameters and porosity of the skin and sublayers. J. Membr. Sci., 66 (1992) 19.

25. L.Gaedt, T.C.Chilcott, M.Chan, T.Nantawisarakul1, A.G.Fane, H.G.L.Coster. Electrical impedance spectroscopy characterization of conducting membranes II. Experimental. J. Membr. Sci., 195 (2002) 169.

26. J.S.Park, T.C.Chilcott, H.G.L.Coster, S.H.Moon. Characterization of BSA-fouling of ionexchange membrane systems using a subtraction technique for lumped data. J. Membr. Sci., 246 (2005) 137.

27. S.Bannwarth, M.Darestani, H.Coster, M.Wessling. Characterization of hollow fiber membranes by impedance spectroscopy. J. Membr. Sci., 473 (2015) 318.

28. P.Sistat, A.Kozmai, N.Pismenskaya, C.Larchet, G.Pourcelly, V.Nikonenko. Low-frequency impedance of an ion-exchange membrane system. Electrochimica Acta, 53 (2008) 6380.

29. Y.Sedkaoui, A.Szymczyk, H.Lounici, O.Arous. A new lateral method for characterizing the electrical conductivity of ion-exchange membranes. J. Membr. Sci., 507 (2016) 34. 
30. S.M.Hosseini, E.Jashni, S.Amani, B.Van der Bruggen. Tailoring the electrochemical properties of $\mathrm{ED}$ ion exchange membranes based on the synergism of $\mathrm{TiO} 2$ nanoparticles-co-GO nanoplates. Journal of Colloid and Interface Science, 505 (2017) 763

31. S.Pawlowski, T.Rijnaarts, M.Saakes, K.Nijmeijer, J.G.Crespo, S.Velizarov. Improved fluid mixing and power density in reverse electrodialysis stacks with chevron-profiled membranes. $J$. Membr. Sci., 531 (2017) 111.

32. M.Pessoa-Lopes, J.G.Crespo, S.Velizarov. Arsenate removal from sulphate-containing water streams by an ion-exchange membrane process. Separation and Purification Technology, 166 (2016) 125.

33. M.Oliot, S.Galier, H.R.de Balmann, A.Bergel. Ion transport in microbial fuel cells: Key roles, theory and critical review. Applied Energy, 183 (2016) 1682.

34. L.Han, S.Galier, H.Roux-de Balmann. Ion hydration number and electro-osmosis during electrodialysis of mixed salt solution. Desalination, 373 (2015) 38.

35. Y.Xu, M.Wang, Z.Ma, C.Gao. Electrochemical impedance spectroscopy analysis of sulfonated polyethersulfone nanofiltration membrane. Desalination, 271 (2011) 29.

36. L.Marbelia, M.Mulier, D.Vandamme, K.Muylaert, A.Szymczyk, I.F.J.Vankelecom. Polyacrylonitrile membranes for microalgae filtration: Influence of porosity, surface charge and microalgae species on membrane fouling. Algal Research, 19 (2016) 128.

37. R.Fortunato, L.C.Branco, C.A.Afonso, J.Benavente, J.G.Crespo. Electrical impedance spectroscopy characterisation of supported ionic liquid membranes. J. Membr. Sci., 270 (2006) 42.

38. L.A.Neves, J.Benavente, I.M.Coelhoso, J.G.Crespo. Design and characterisation of Nafion membranes with incorporated ionic liquids cations. J. Membr. Sci., 347 (2010) 42.

39. M.T.Darestani, T.C.Chilcott, H.G.L.Coster. Electrical impedance spectroscopy study of piezoelectric PVDF membranes. Journal of Solid State Electrochemistry, 18 (2014) 595.

40. A.V.Volkov, V.V.Volkov, V.S.Khotimskii. Membranes based on poly[(1-trimethylsilyl)-1propyne] for liquid-liquid separation. Polym. Sci. Ser. A, 51 (2009) 1367.

41. V.S.Khotimsky, M.V.Tchirkova, E.G.Litvinova, A.I.Rebrov, G.N.Bondarenko. Poly[1trimethylgermyl)-1-propyne] and poly[1-(trimethylsilyl)-1-propyne] with various geometries: their synthesis and properties. J. Polym. Sci., Part A, 41 (2003) 2133.

42. V.S.Khotimsky, S.M.Matson, E.G.Litvinova, G.N.Bondarenko, A.I.Rebrov. Synthesis of poly(4-methyl-2-pentyne) with various configurations of macromolecular chains. Polym. Sci. Ser. A, 45 (2003) 740. 
43. A.V.Volkov, E.V.Fedorov, A.O.Malakhov, V.V.Volkov. Vapor sorption and dilation of poly[(1-trimethylsilyl)-1-propyne] in methanol, ethanol and propanol. Polym. Sci. Ser. B, 44 (2002) 158.

44. A.Malakhov, A.Volkov. Application of Coupled Solution-Diffusion Model in Organic Solvent Nanofiltration: Positive and Negative Rejection of Solutes. Separation Science and Technology, 50 (2015) 2198.

\section{Prediction of liquid permeability $(P)$ by electrical resistance $(R)$ measurement}

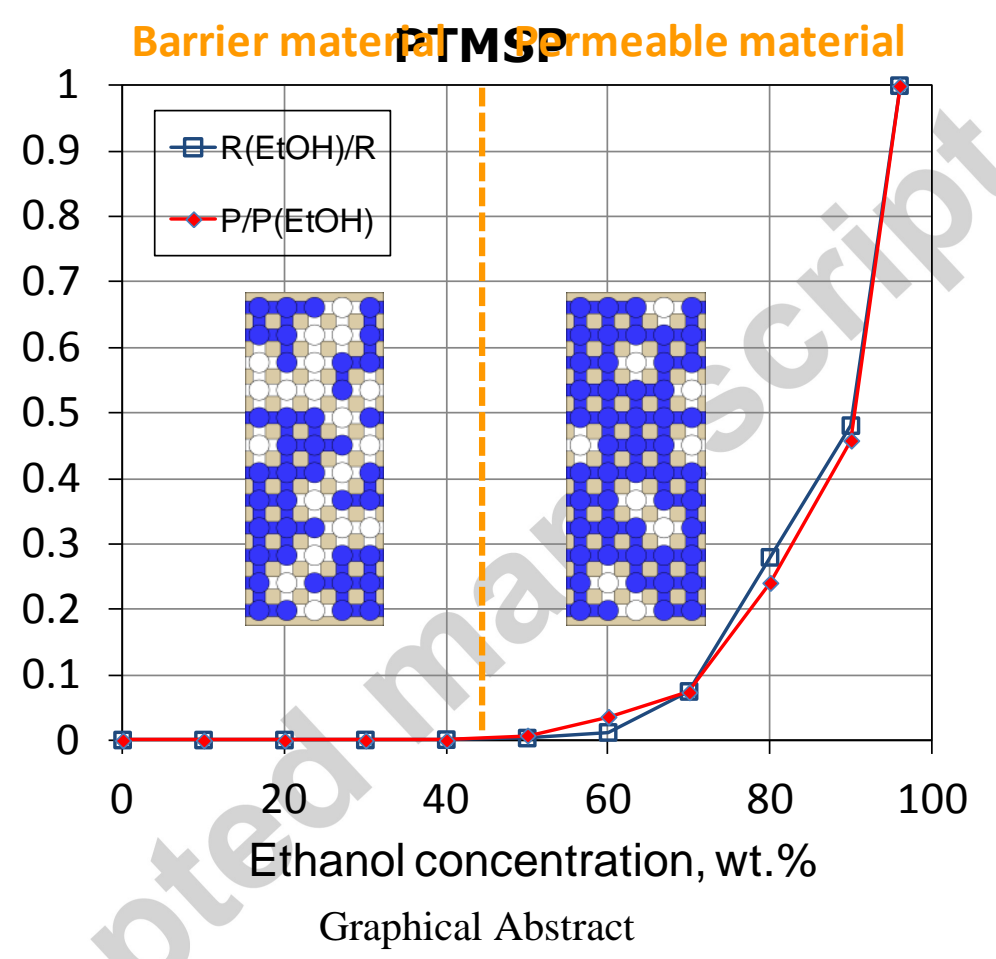

\section{Highlights}

- The formation of percolation clusters inside dense polymer membranes was highlighted from the determination of the membrane electrical resistance.

- A good correlation was obtained between electrical resistance and permeability measurements performed for various water/ethanol mixtures.

- The comparison with sorption experiments indicated that a critical ethanol concentration in the liquid phase was required so as to obtain percolation clusters through the membranes. 